\title{
COINTEGRATION ANALYSIS OF THE FOREIGN EXCHANGE RATE PAIRS
}

\author{
Mária Bohdalová ${ }^{1}$, Michal Greguš
}

\begin{abstract}
Due to certain economic factors, Hungary and Poland-the two Central European (CE) countrieshave not successfully adopted the Euro currency. We aim to investigate the dependency of the two CE currencies, HUF and PLZ, against the USD and the linking mechanism between them. Cointegration analysis is commonly used as a common econometric technique for evaluating such efficiency.

In this article, we discuss the cointegration analysis of the selected foreign exchange (FX) rate pairs. Using bivariate error correction model (ECM), we investigate spot FX rate pairs of HUF/USD and PLZ/USD. The results from ECM are used in impulse response model for prediction of the new equilibrium after the exogenous shocks affecting the processes at time $t$.

We have found that HUF reacts more closely with the change in USD and that HUF and PLZ are very unlikely to be cointegrated. Nonetheless, we have found the period when both spot exchange rates are weekly cointegrated, which was after August 2011. Although contributions are low, the analytical results are still statistically significant for other researches to be conducted with fractal analysis of these FX rates.
\end{abstract}

JEL Classification Numbers: C01, G17, C15, G30, G11, DOI: http://dx.doi.org/10.12955/cbup.v2.497

Keywords: cointegration, ECM, FX rates, impulse response model

\section{Introduction}

Cointegration analysis of the foreign exchange rates is a commonly used econometric technique for examination of the foreign exchange market efficiency. The market is efficient if the price of financial instruments reflects all available and relevant information for the pricing process (Fama, 1970; Kühl, 2007). This paper aims to investigate the currencies of the CE (Hungary and Poland), which were preparing to adopt the Euro currency, but due to the impact of various economic factors the adoption of the Euro has not been accomplished yet. We show that HUF, compared to PLZ, reacts more sharply to changes in the USD evolution.

\section{Literature review}

Many authors are interested in the study of foreign exchange market efficiency. Granger (1986) has recommended testing the market efficiency using cointegration analysis for long-run co-movements between time series at the end of the 1980s. According to the Granger's representation theorem, cointegration means that two or more time series fluctuate conjointly in a long-term relationship that can be seen as an equilibrium relationship, to which an error correction term automatically belongs (Granger, 1983; Engle \& Granger, 1987). Short-run deviations from that long-run relationship result in an automatic adjustment process that causes the variables to return to their long-term equilibrium relationship. Thus, the error correction term contains information regarding the future movements of one variable based on past prices (Kühl, 2007; Granger, 2001).

As Alexander (2008) wrote, two exchange rates are highly unlikely to be cointegrated. However, there is some empirical evidence of cointegration between two or more exchange rates from Baillie \& Bollerslev (1994), Kouretas \& Zarangas (1998), Lajaunie \& Naka (1997), Phengpis (2006), Kühl (2007). Kühl (2007) has been investigating the market efficiency of the foreign exchange market since the introduction of the Euro using the cointegration methodology. Kühl (2007) had all currencies denominated in USD. The reason for which co-movements between two exchange rates should be examined explicitly is a speculative market with them in the pairs trading strategy (Vidyamurthy, 2004; Liew \& Wu, 2013).

\footnotetext{
${ }^{1}$ Mária Bohdalová, Comenius University, Bratislava, Slovakia, maria.bohdalova@fm.uniba.sk

${ }^{2}$ Michal Greguš, Comenius University, Bratislava, Slovakia, michal.gregus@fm.uniba.sk
} 
In our study, we investigate the dependency between exchange rates of two Central European countries: HUF/USD and PLZ/USD, and the mechanisms that tie these cointegrated series together. It is possible to use two measures of dependency: correlation and cointegration. Pearson correlation coefficient measures only linear associations, and it has huge limitations (Embrechts, McNeil, \& Straumann, 2002). Although it is possible to use copula approach for constructing unconditional joint distributions that reflect almost any type of dependence, it ignores dynamic properties such as autocorrelation in return (Alexander, 2008). The presence of cointegration implies that there is a longterm association between the time series. Thus, we use error correction model (ECM) that has a selfregulating mechanism, whereby deviations from the long-term equilibrium are automatically corrected (Alexander, 2008).

\section{Data and methodology}

In this article, we analyze two selected spot exchange rates: Polish Zloty (PLZ) and Hungarian Forint (HUF) against US dollar (PLZ/USD and HUF/USD). The analyzed sample period was from the $2^{\text {nd }}$ of January 2009 until the $8^{\text {th }}$ of May 2014 in daily frequency. The data were obtained from statistical data warehouse of the bank of England ${ }^{3}$. All the estimation processes have been carried out in Wolfram Mathematica (Ver. 10).

\section{Cointegration}

The time series are cointegrated if they have the same order of integration and if a linear combination of these time series exist as stationary (integrated of order one). Originally, Engle \& Granger (1987) proposed a two-step procedure to estimate cointegration relations. In this two-step procedure, which is mostly applied to $n$ time series $X_{1}, \ldots X_{n}$, we choose one of these variables as the dependent variable, for example $X_{1}$ and then this variable is regressed on the other variables. After the first step, the resulting error series $\varepsilon=\left\{\varepsilon_{t}\right\}$ is tested for stationarity (Kühl, 2007; Alexander, 2008):

$$
X_{1, t}=\beta_{1}+\beta_{2} X_{2 t}+\ldots+\beta_{n} X_{n t}+\varepsilon_{t}
$$

If the null hypothesis of non-stationarity is rejected, it can be said that the time series are cointegrated with cointegration vector $\left(1,-\hat{\beta}_{2}, \ldots,-\hat{\beta}_{n}\right)$, where $\beta_{i}$ are the cointegration parameters (Engle \& Granger, 1987). In other words,

$$
Z=X_{1}-\hat{\beta}_{2} X_{2}-\ldots-\hat{\beta}_{n} X_{n}
$$

is the stationary linear combination of integrated variables whose mean represents the long equilibrium.

Cointegration means that both series move together in the long-run and cannot drift apart very far from each other (Granger, 1981). Consequently, the error term resulting from the linear combination of the aforementioned time series can be seen as an equilibrium error. This equilibrium error quantifies the deviation of the time series from their common long-run relationship (Granger, 1986). Hence, deviations from the linear combination can only occur randomly and unsystematically (Kühl, 2007).

If a long-run relation between time series processes exists and if the equilibrium error is stationary, there must be a mechanism that brings the system back to equilibrium in the face of an innovation. In this context, Granger (1983) analytically illustrates that the consideration of a cointegration relationship is equivalent to the existence of an error correction mechanism-Granger's representation theorem (Kühl, 2007).

\footnotetext{
${ }^{3}$ http://www.bankofengland.co.uk
} 


\section{Error Correction Model}

Error correction model (ECM) provides a short-term analysis of dynamic correlations. The connection between the two stages is that the disequilibrium term $Z$ that is used in the ECM is determined during the first stage by equation (2).

The reason for the name error correction stems from the fact that the model is structured so that the short term deviations from the long-term equilibrium will be corrected. We illustrate this on a case where there are two cointegrated time series X and Y. Here an ECM takes the form (Alexander, 2008):

$$
\begin{gathered}
\Delta X_{t}=\alpha_{1}+\sum_{i=1}^{m} \beta_{11}^{i} \Delta X_{t-i}+\sum_{i=1}^{m} \beta_{12}^{i} \Delta Y_{t-i}+\gamma_{1} Z_{t-1}+\varepsilon_{1 t} \\
\Delta Y_{t}=\alpha_{2}+\sum_{i=1}^{m} \beta_{21}^{i} \Delta X_{t-i}+\sum_{i=1}^{m} \beta_{22}^{i} \Delta Y_{t-i}+\gamma_{2} Z_{t-1}+\varepsilon_{2 t},
\end{gathered}
$$

where $Z$ is the disequilibrium term given by equation (2), and the lag lengths and coefficients are determined by ordinary least squares (OLS) regression.

\section{Results and Discussion}

Time series of FX rates are highly correlated with each other as illustrated by Figure 1 (left). The data on the left chart are adjusted for better comparison using linear transformation (FX rates HUF/USD are shifted +100 , and FX rates PLZ/USD are scaled by 100). Black line is used for FX rates HUF/USD and grey color is used for FX rates PLZ/USD. We can see that both FX rates share similar comovement.

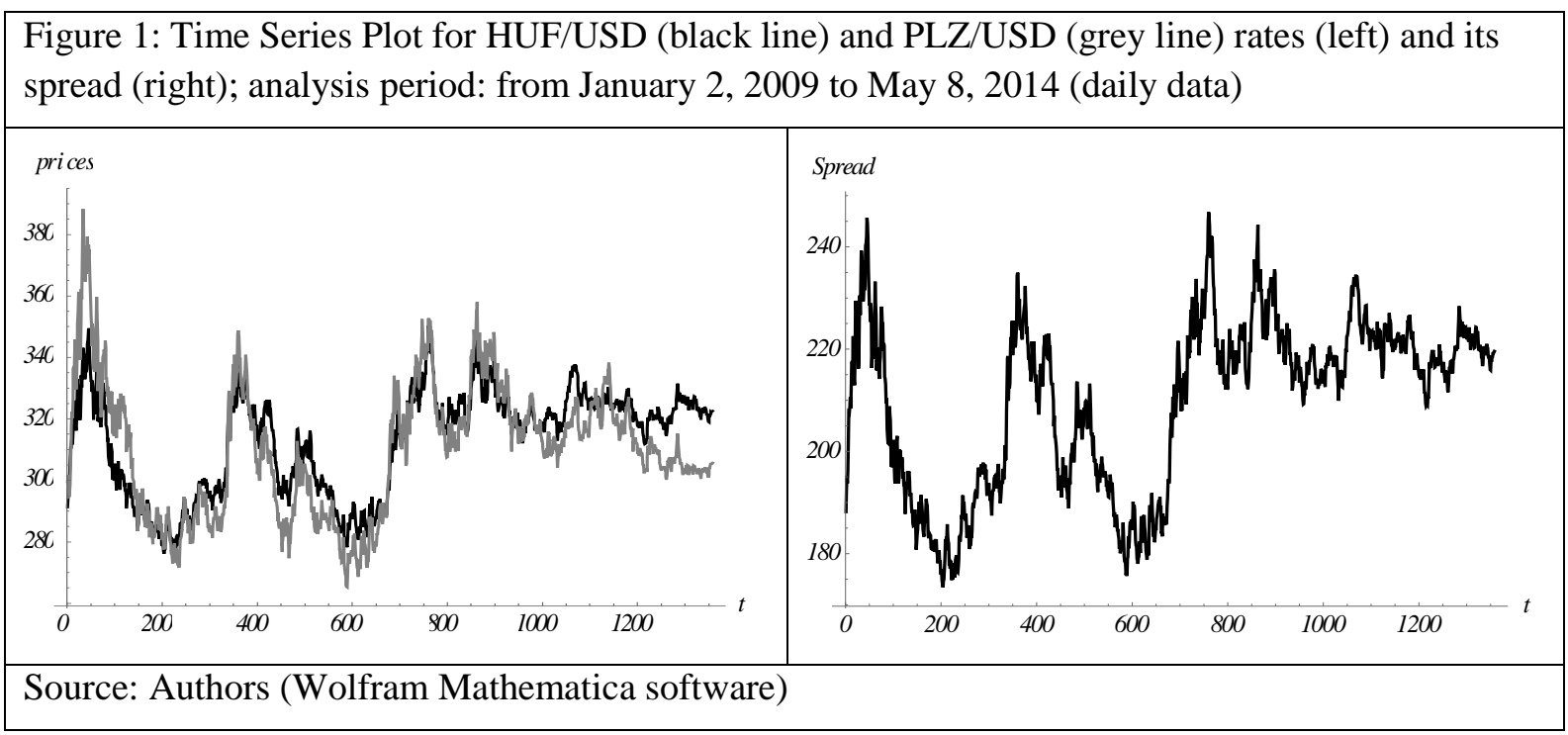

Figure 1 (right chart) shows the spread as a difference between HUF/USD and PLZ/USD. The figure of the FX rates pairs spread suggests two major kinds of oscillations, until August 31, 2011 and beyond, when the Euro depreciated by $7.4 \%$ against the US dollar. The main driving factors were changes in the perception of the sustainability of public finances in some Euro area Member States and in the United States as well as movements in yield differentials between the two economies (ECB Monthly bulletin, 2011). At the end of 2011, the IMF/EU bail-out program lapsed and it was replaced by Post Program Monitoring and Article IV Consultations on overall economic and fiscal processes. At the same time, the government of Hungary turned to the IMF and the EU to obtain financial backstop to support its efforts to refinance foreign currency debt and bond obligations. However, Budapest's rejection of EU and IMF economic policy recommendations led to a breakdown in talks 
with the lenders in late 2012. The global demand for high yields have helped Hungary to obtain funds on international markets since that time. Hungary's progress in reducing its deficit under 3\% of GDP led the European Commission in 2013 to permit Hungary for the first time since joining the EU in 2004 to exit the Excessive Deficit Procedure ${ }^{4}$. During the first quarter of year 2012 the U.S. dollar depreciated broadly against most currencies, with the exception of the Japanese yen. The dollar's depreciation reflected a number of factors, including policy actions by global central banks and investor perceptions of an improving global growth outlook (Sack, 2012).

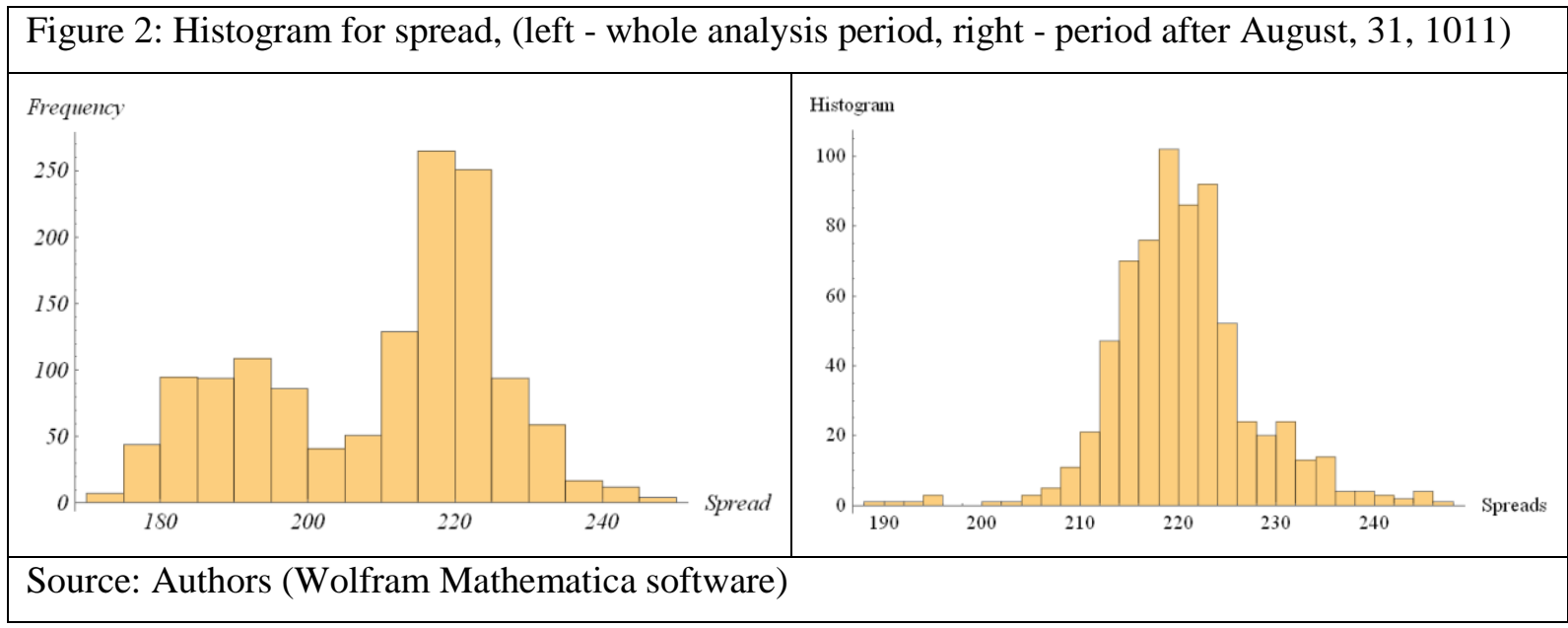

Figure 2 shows histogram for the whole analysis period (left chart) and for period from August 31, 2011 onward. Histogram for the whole analysis period exhibits two peaks, and the histogram for data from August 31, 2011 exhibits Student $t$ distribution with mean equal to 220.132, standard deviation equal to 5.245, and with degree of freedom equal to 3.938. Kuiper test does not reject hypothesis about Student $t$ distribution ( $p$-value is 0.251 ). For these reasons, we will analyze only the period after August 31, 2011.

Cointegration and correlation analysis are based on different concepts. High correlation does not imply high cointegration, nor does high cointegration imply high correlation. Cointegration analysis consists of two stages (Alexander, 2008):

1. The aim of the first stage is to establish a long-term equilibrium relationship between prices. The purpose of this analysis is to identify a stationary linear combination of the prices, which best describes the long-term equilibrium relationship between them.

2. The aim of the second stage is to use error correction model (ECM) of returns for the longterm equilibrium.

Stationarity of the differences for the both FX rates and for their spreads for data after August $31^{\text {st }}$, 2011 were tested using Unit root tests (Dickey-Fuller and Phillips-Perron). Both tests confirmed that our time series came from a weakly stationary process with significance $5 \%$.

Now we estimate a bivariate ECM (Alexander, 2008) on the two FX rates, and we use this model to identify the Granger causal flows between them. Furthermore, we estimate the impulse response function following exogenous shocks. We have used spread as a disequilibrium term.

\footnotetext{
${ }^{4}$ http://www.indexmundi.com/hungary/economy_profile.html
} 
CBU I NTERNATI ONAL CONFERENCE ON I NNOVATION, TECHNOLOGY TRANSFER AND EDUCATION

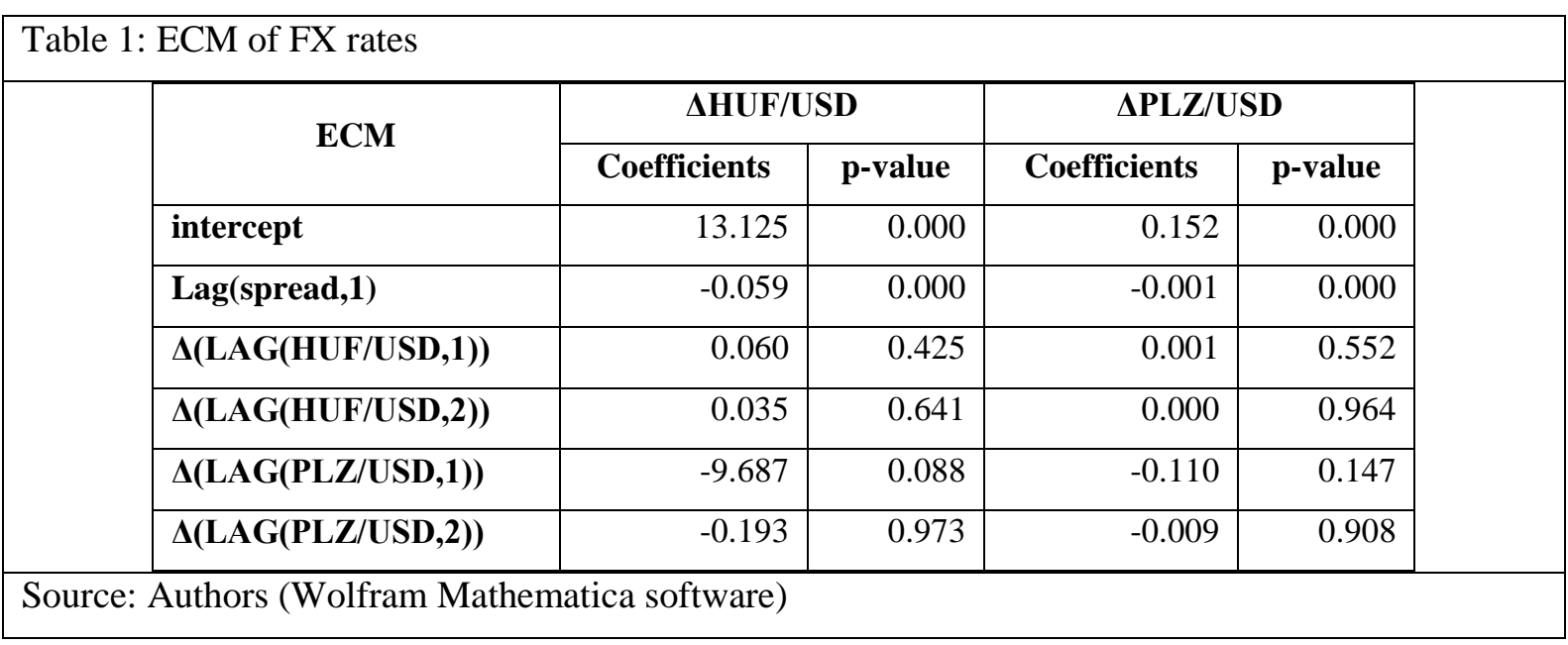

Table 1 shows estimated coefficients for ECM for first two lags of each dependent variable. We have found out that only the coefficient for intercept and the first lag for spread are significant at $5 \%$ for both time series. Table 2 shows results for ECM testing of the models by removing variables that are non-significant at 5\%. These results indicate that both time series have significant autocorrelation. Equilibrium adjustments are influenced only via significant lagged spread for both exchange rates.

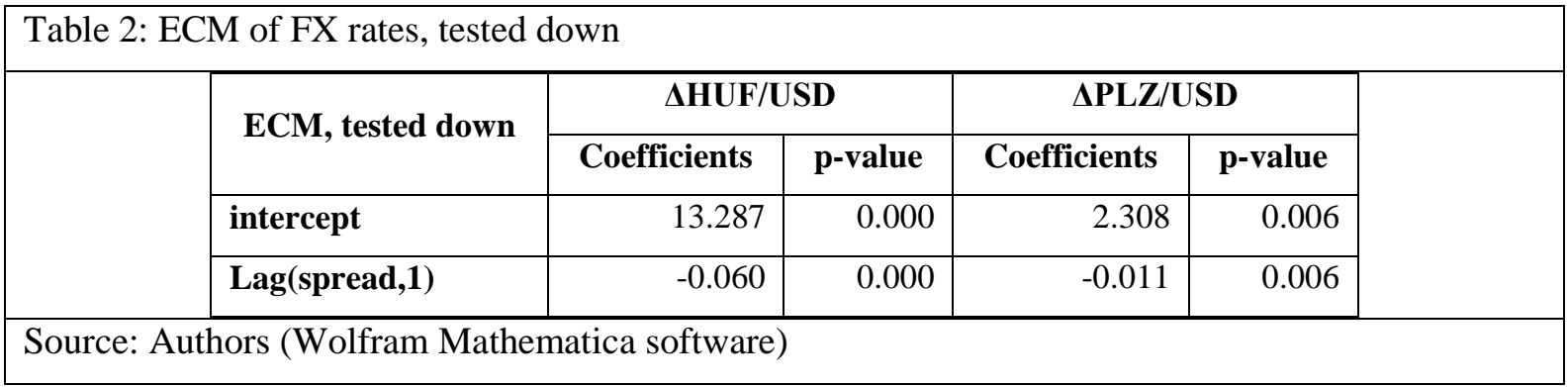

Now we compute the impulse response functions of both exchange rates. Error correction mechanism can be rewritten as:

$$
\begin{aligned}
& \mathrm{HUF} / \mathrm{USD}_{t}=13.287+0.9399 \mathrm{HUF} / \mathrm{USD}_{t-1}+0.0601 \mathrm{PLZ} / \mathrm{USD}_{t-1}+\varepsilon_{1, t} \\
& \mathrm{PLZ} / \mathrm{USD}_{t}=2.3082-0.0109 \mathrm{HUF} / \mathrm{USD}_{t-1}+1.0101 \mathrm{PLZ} \mathrm{USD}_{t-1}+\varepsilon_{2, t} \text {, }
\end{aligned}
$$

where $\varepsilon_{1, t}$ and $\varepsilon_{2, t}$ are OLS residuals.

Figure 3: Impulse Response Function. Impulse shock: HUF/USD +10 bp, PLZ/USD +0.5 bp left: HUF/USD (upper line) and Spread (lower line), right: PLZ/USD

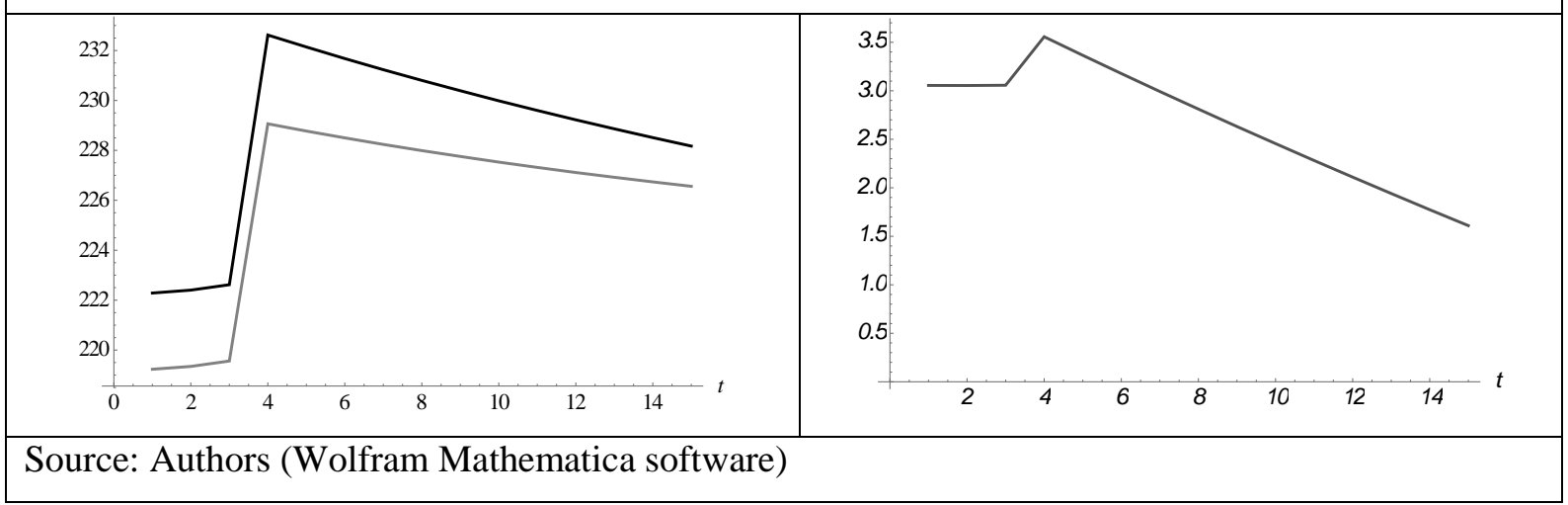

Using these equations we have investigated the response of the FX rates and the spread to a $\pm 10 \mathrm{bp}$ shock on the HUF/USD rates at the same time as a $\pm 0.5 \mathrm{bp}$ on the PLZ/USD rates (see Figure 3 for 
positive shocks and Figure 4 for negative shocks). We do not assume further shocks during next 15 days. Horizontal axis refers to the number of days.

Figure 3 shows the expected path of the future FX HUF/USD rates (upper line) and spreads (lower line) after the positive shocks. Their new equilibrium will be approximately at $228 \mathrm{bp}$. New equilibrium for PLZ/USD FX rates will be approximately 1.6 bp. New equilibrium after negative shocks will be $218 \mathrm{bp}$ for HUF/USD and 2.4 bp for PLZ/USD FX rates. The spreads after positive shocks are 226.56 bp respectively 215.65 bp after negative shocks.

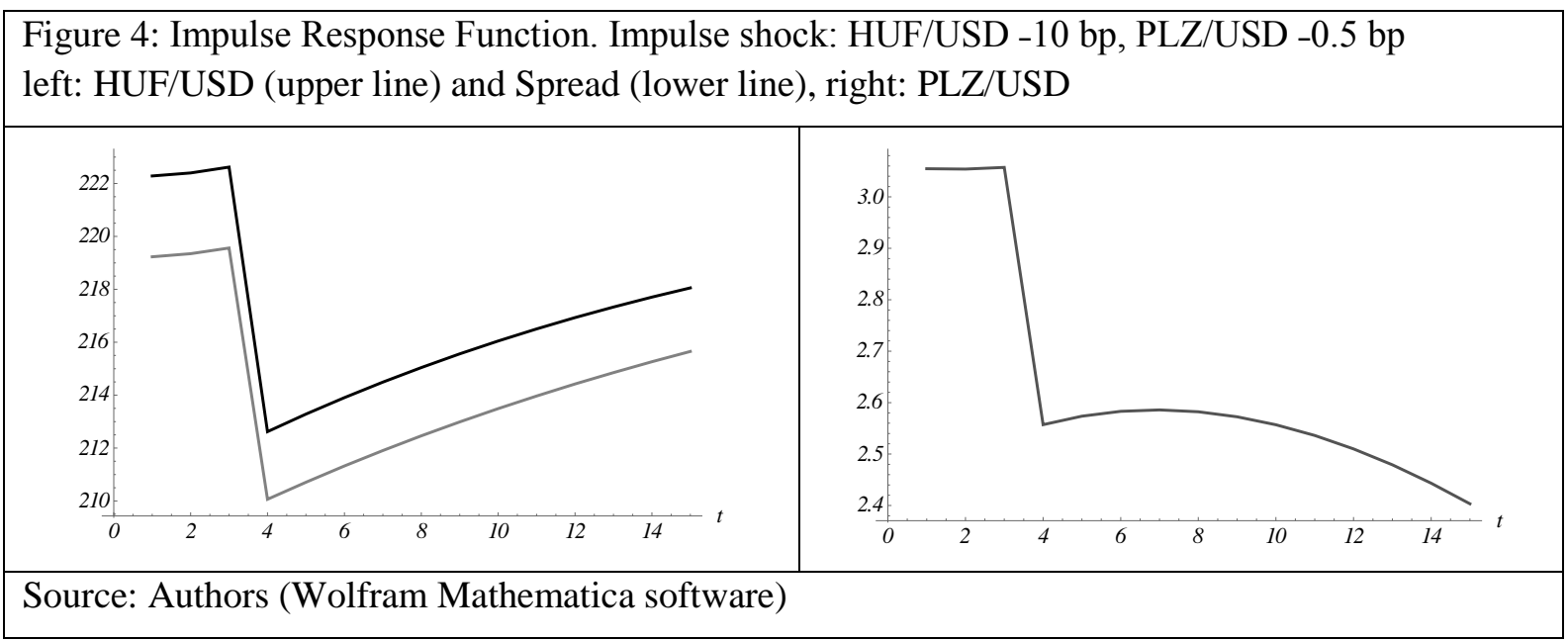

\section{Conclusion}

Using bivariate ECM, this paper describes the study of the cointegration between two daily Central European countries' exchange rates, HUF and PLZ, against the USD. We have found a period during which HUF/USD and PLZ/USD were weekly cointegrated; this period was after August 2011. Granger (1986) provided an argument that a market is not efficient if cointegration between pairs of exchange rates can be considered because the observation of cointegration means the predictability of at least one exchange rate.

From our analysis, it can be concluded that the contribution of the PLZ/USD is low to the HUF/USD and vice versa. Contributions are low, but statistically significant for other researches to be made with fractal analysis of these exchange rates.

\section{Acknowledgements}

The work on this paper has been supported by VEGA grant agency, grant number 1/0279/11 .

\section{References}

Alexander, C. (2008). Market Risk Analysis. Chichester, England: John Wiley \& Sons, Inc.

Baillie, R.T., \& Bollerslev, T. (1994). Cointegration, Fractional Cointegration, and Exchange Rate Dynamics. The Journal of Finance, 49(2). Retrieved from https://www.msu.edu/user/baillie/J_Finance.1994.pdf

Caldeira, J., Moura, G. V. (2013, January 4). Selection of a Portfolio of Pairs Based on Cointegration: A Statistical Arbitrage Strategy. doi: 10.2139/ssrn.2196391

ECB Monthly Bulletin (2011, December). European Central Bank. Retrieved from http://www.ecb.europa.eu/pub/pdf/mobu/ mb201112en.pdf

Embrechts, P., McNeil, A. J., \& Straumann, D. (2002). Correlation and Dependence in Risk Management: Properies and Pitfalls. In: M. A. H. Dempster (Ed.), Risk management: Value at Risk and Beyond (pp. 176-223). West Nyack, NY, USA: Cambridge University Press.

Engle, R. F., \& Granger, C. W. J. (1987, March). Co-Integration and Error Correction: Representation, Estimation, and Testing. Econometrica, 55(2), 251-276. Retrieved from http://links.jstor.org/sici?sici=0012-9682\%28198703\%2955\%3 A2\%3C251\%3ACAECRE\%3E2.0.CO\%3B2-T 
Fama, E. F. (1970). Efficient Capital Markets: A Review of Theory and Empirical Work. The Journal of Finance, 25, 383417.

Gatev, E., Goetzmann, W. N., \& Rouwenhorst, K. G. (2006, February). Pairs Trading: Performance of a Relative Value Arbitrage Rule. Yale ICF Working Paper No. 08-03. doi: 10.2139/ssrn.141615

Granger, C. W. J. (1980). Testing for causality. A personal Viewpoint. Journal of Economic Dynamics and Control, 2, 329352. doi: 10.1016/0165-1889(80)90069-X

Granger, C. W. J. (1983). Co-Integrated Variables and Error-Correcting Models. UCSD Discussion Paper No. 83-13a.

Granger, C. W. J. (1986). Developments in the study of cointegrated economic variables. Oxford Bulletin of Economics and Statistics, 48(3). Retrieved from http://homepage.ntu.edu.tw/ kslin/macro2009/Granger\%201986.pdf

Granger, C. W. J (2001). Essays in econometrics: collected papers of Clive W. J. Granger. Cambridge, MA, USA: Harvard University Press.

Kouretas, G. P., \& Zarangas, L. P. (1998). A cointegration analysis of the official and parallel foreign exchange markets for dollars in Greece. International Journal of Finance and Economics, 3, 261-276. doi: 10.1002/(SICI)1099-1158(199807) 3:3<261::AID-IJFE71>3.0.CO;2-Z

Kühl, M. (2007). Cointegration in the Foreign Exchange Market and Market Efficiency since the Introduction of the Euro: Evidence based on bivariate Cointegration Analyses. Discussion Papers, CEGE, Georg-August-University of Göttingen, 68. Retrieved from http://www.user.gwdg.de/ cege/Diskussionspapiere/68

Lajaunie, J. P., \& Naka, A. (1997). Re-examining Cointegration, Unit Roots and Efficiency in Foreign Exchange Rates. Journal of Business Finance and Accounting, 24, 363-374. doi: 10.1111/1468-5957.00109

Liew, R. Q., \& Wu, Y. (2013). Pair trading: A copula approach. Journal of Derivatives \& Hedge Funds, 19(1), 12-30. Retrieved from www.palgrave-journals.com/jdhf/

Phengpis, Ch. (2006). Market efficiency and cointegration of spot exchange rates during periods of economic turmoil: Another look at European and Asian currency crises. Journal of Economics and Business, 58, $323-342$. doi:10.1016/j.jeconbus.2005.10.003

Sack, B. (2012). Treasury and Federal Reserve Foreign Exchange Operations. Retrieved from http://www.newyorkfed.org/newsevents/news/markets/2012/fxq112.pdf

Stern, D. I. (2011). From Correlation to Granger Causality. Crawford School Research Paper No. 13. doi: 10.2139/ssrn.1959624.

Vidyamurthy, G. (2004). Pairs trading. Quantitative Methods and Analysis. New Jersey, USA: John Wiley \& Sons, Inc.

Xie, W., \& Wu, Y. (2013, January 30). Copula-Based Pairs Trading Strategy. Asian Finance Association (AsFA) 2013 Conference. doi: 10.2139/ssrn.2209209 